В. О. Яцук, Р. О. Матвіїв

Національний університет “Львівська політехніка", кафедра метрології, стандартизації та сертифікації

\title{
МОДЕЛЮВАННЯ ПРОЦЕСУ АВТОМАТИЧНОГО КОРИГУВАННЯ ПОХИБОК КАЛІБРАТОРІВ НАПРУГИ ПОСТІЙНОГО СТРУМУ
}

\author{
() Яиук B. O., Матвї̈в Р. O., 2016
}

Запропоновано метод коригування адитивних похибок в калібраторах напруги постійного струму на основі методу комутаційного інвертування $з$ додатковим джерелом зразкової напруги. Розроблено структурну схему калібратора напруги 3 автоматичним коригуванням адитивних похибок і досліджено їі методом комп'ютерного моделювання.

Ключові слова: калібратор напруги, адитивна похибка, автоматичне коригування, комутаційне інвертування.

\section{DESIGN OF AUTOMATIC ERROR CORECTION FOR DC VOLTAGE CALIBRATOR}

(C) Yatsuk V., Matviiv R., 2016

A method of additive error correction in DC voltage calibrator on the basis of inverting commutation method with additional voltage source is proposed. The structural diagram of the calibrator with automatic correction of additive errors is developed. The investigation of proposed diagram using computer simulation is conducted.

Key words: voltage calibrator, additive error, automatic correction, inverting commutation method.

\section{Вступ}

Адитивні похибки калібраторів напруги постійного струму (КНПС) виникають переважно від зміщення нульового рівня функції перетворення аналогових електронних вузлів у колі перетворення і від спаду напруги в лініях зв’язку між окремими вузлами. При цьому адитивні похибки, зумовлені еквівалентними напругами зміщення операційних підсилювачів, в КНПС додаються до значення зразкової напруги і перетворюються на мультиплікативну складову похибки через застосування в них кодо-керованих подільників. Адитивні складові похибки вихідних масштабних перетворювачів КПНС зумовлюють адитивне зміщення його вихідної напруги. Окрім того, вони можуть виникати також під час проходження струмів живлення різних вузлів пристрою через опори спільних ліній зв'язку між ними, і для їх зменшення використовують конструктивнотехнологічні способи.

\section{1. Огляд літературних джерел}

У нормальних умовах експлуатації коригування похибок зазвичай проводиться в ручному режимі роботи зміщенням функції перетворення КНПС за допомогою введення коригувальної величини, що дорівнює за значенням, і протилежної за знаком адитивної похибки. При цьому коригування адитивної похибки проводиться в ручному і автоматичному режимах.

У роботах $[1,2]$, для коригування адитивних похибок цифрових вольтметрів у робочих умовах експлуатації використано метод автоматичного коригування з комутаційним інвертуванням опорної напруги вбудованого калібратора напруги. Через коригування адитивних похибок вбудованого калібратора напруги в цифровій частині вольтметра такий метод не може бути 
застосованим для автоматичного коригування адитивної складової похибки (АСП) власне КНПС. У статті [3] проаналізовано частотні властивості калібраторів напруги та імітаторів електричного 3 коригуванням АСП за методом подвійного комутаційного інвертування або комутації вимірювальних струмів. При цьому не подано рекомендацій щодо вибору параметрів елементної бази під час реалізації КНПС.

Для коригування похибок також застосовують метод уведення експериментальних та розрахункових поправок. Зокрема у статті [4] запропоновано метод алгоритмічного коригування АСП усього вимірювального тракту перетворення з використанням додаткового такту визначення і запам'ятовування значення похибки з подальшим іï коригуванням. Однак в переносних КНПС такий метод практично ускладнює реалізацію через необхідність використання додаткового цифро-аналогового перетворювача, АСП якого визначатимуть нескориговане значення похибки. В [5] показано, що застосувавши ітераційну процедуру коригування похибок за відповідним алгоритмом, можна скоригувати похибку за таким ітераційним алгоритмом вимірювання. Проте застосування ітераційних процедур в калібраторах - пристроях для відтворення, а не вимірювання напруги постійного струму суттєво ускладнює їх реалізацію через необхідність використання трудомісткої операції розрахунків та уведення поправок для кожного із встановлюваних значень кодів керування КНПС.

На практиці для коригування АСП застосовують спеціальний режим встановлення нульового рівня, який проводиться при двох різних конфігуруваннях схеми калібратора $[6,7]$. Тому з метою застосування розглянутих методів коригування АСП у калібраторах напруги необхідно їх дослідити і вдосконалити.

\section{2. Постановка завдання}

Метою роботи є дослідження структури калібраторів напруги постійного струму з використанням автоматичного режиму коригування адитивних складових похибок.

\section{3. Аналіз впливу адитивних складових похибок}

На рис. 1 подано структурну схему калібратора напруги постійного струму, на якій показано джерела виникнення адитивних похибок.

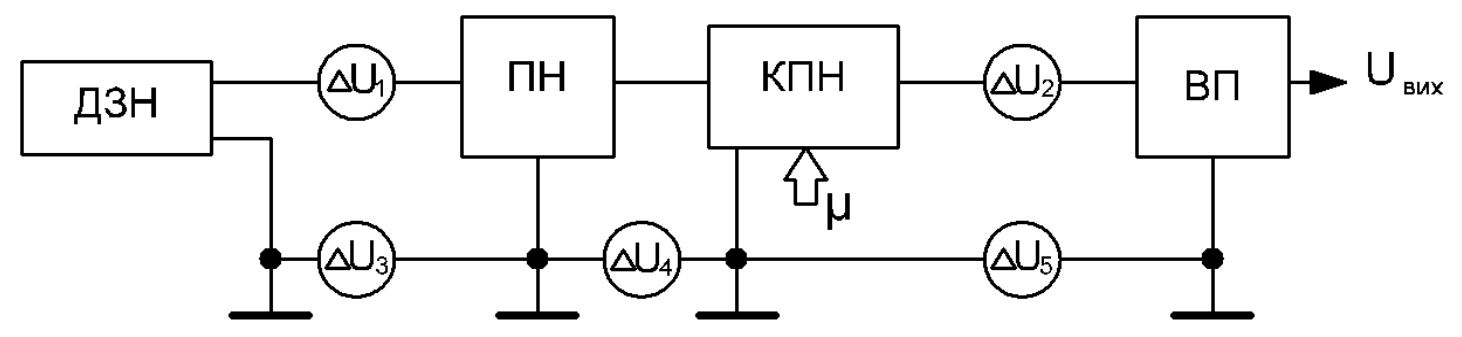

Рис. 1. Структурна схема калібратора напруги постійного струму з джерелами адитивних похибок

Структурна схема містить послідовно з'єднані джерело зразкової напруги ДЗН, підсилювач напруги ПН, кодо-керований подільник напруги КПН і вихідний підсилювач ВП. Адитивні похибки $\Delta \mathrm{U}_{1}$ i $\Delta \mathrm{U}_{2}$ виникають від зміщення нульового рівня відповідно підсилювачів ПН і ВП. Адитивні похибки $\Delta \mathrm{U}_{3}, \Delta \mathrm{U}_{4} \mathrm{i} \Delta \mathrm{U}_{5}$ виникають у спільних лініях зв'язку між окремими елементами $\mathrm{i}$ визначаються за виразом:

$$
\Delta U_{i}=I_{i} \cdot R_{\pi i},
$$

де $I_{i}-$ струм, що проходить через лінії зв'язку; $R_{n i}-$ опір ліній зв'язку.

Зменшення значень цих АСП досягають конструктивними методами, тобто зменшенням значення опору ліній зв'язку і зменшенням значення струмів живлення між окремими вузлами. 
Значення вихідної напруги в результаті впливу адитивних похибок від зміщення нульового рівня операційних підсилювачів (ОП) визначається виразом:

$$
U_{\text {вих }}=\left[\left(U_{0}+\Delta U_{1}\right) \cdot K_{1} \cdot \mu+\Delta U_{2}\right] \cdot K_{2},
$$

де $U_{0}$ - значення зразкової напруги; $K_{1}, K_{2}$ - коефіцієнт передавання підсилювачів; $\mu$ - коефіцієнт перетворення КПН.

Відповідно загальну адитивну похибку описують виразом:

$$
\Delta U=\left(\Delta U_{1} \cdot K_{1} \cdot \mu+\Delta U_{2}\right) \cdot K_{2} .
$$

3 аналізу виразу (3) видно, що зміщення нульового рівня операційного підсилювача ПН створює мультиплікативну складову похибки, значення якої залежить від коефіцієнта перетворення КПН $\mu$. Адитивна складова похибки, зумовлена зміщенням нульового рівня вихідного підсилювача, не залежить від значення $\mu$. Коригувати вплив зміщення нульового рівня ПН і ВП можна внутрішнім коригуванням ОП або введенням коригувальних напруг на входах ПН і ВП відповідно. Коригувати складову $\Delta \mathrm{U}_{1}$ можна також зміною коефіцієнта передавання ПН.

Проведений аналіз показав, що автоматично коригувати зміщення нульового рівня ОП найдоцільніше методом подвійного комутаційного інвертування.

\section{4. Проектування структурної схеми}

На рис. 2 подано структурну схему калібратора напруги, в якій для коригування впливу напруг зміщення ОП використано метод подвійного комутаційного інвертування 3 додатковим джерелом зразкової напруги. Структурна схема містить джерела зразкових напруг ДЗН1 і ДЗН2, вхідний підсилювач ВхП, кодокерований подільник напруги КПН, вихідний підсилювач ВихП, комутаційні ключі К1-К3, тактовий генератор ТГ і фільтр Ф.

На виході вихідного підсилювача залежно від сигналу тактового генератора формуються напруги:

$$
\begin{array}{cc}
U_{1}=\left[\left(U_{0+}+\Delta U_{1}\right) \cdot K_{1} \cdot \mu+\Delta U_{2}\right] \cdot K_{2}, & 0 \leq t \leq \frac{T}{2} ; \\
U_{2}=-\left[\left(U_{0-}+\Delta U_{1}\right) \cdot K_{1} \cdot \mu+\Delta U_{2}\right] \cdot K_{2}, & \frac{T}{2} \leq t \leq T,
\end{array}
$$

де $T$ - період імпульсів тактового генератора ТГ.

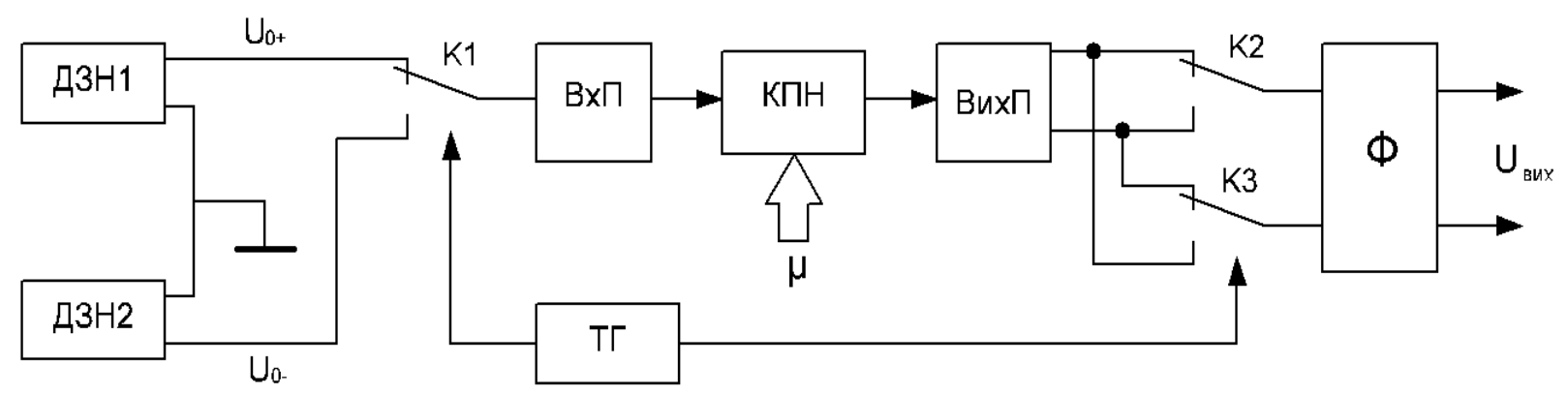

Рис. 2. Структурна схема калібратора напруги з додатковим джерелом зразкової напруги

Відповідно на виході ВихП формуються різнополярні сигнали, а на вхід фільтра надходять сигнали однієї полярності в результаті комутації ключів К2, К3. При цьому на виході фільтра напруга визначається виразом:

$$
U_{\text {вux }}=\frac{U_{1}-U_{2}}{2}=\frac{U_{0+}-U_{o-}}{2} \cdot K_{1} \cdot \mu \cdot K_{2} .
$$

Відповідно на виході фільтра адитивні похибки від зміщення нульового рівня операційних підсилювачів повністю компенсуються. 


\section{5. Дослідження структури калібратора напруги постійного струму 3 автоматичним коригуванням адитивних похибок}

Запропоновану схему калібратора напруги постійного струму з автоматичним коригуванням АСП методом комутаційного інвертування досліджено комп'ютерним методом у середовищі ElectronicWorkbench відповідно до моделі, поданої на рис. 3.

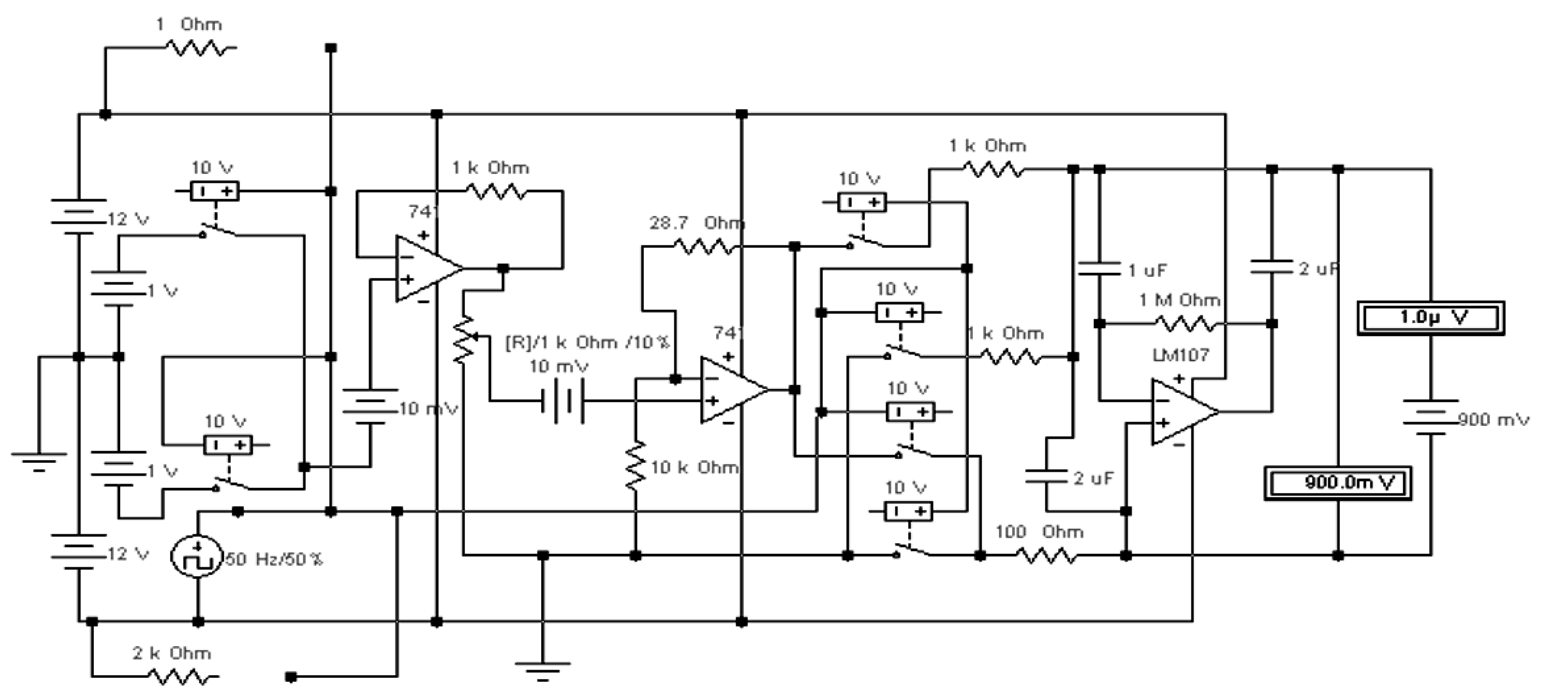

Рис. 3. Схема-модель для дослідження калібратора напруги постійного струму з автоматичним корегуванням похибок

Комутація вхідного підсилювача здійснюється двома ключами на замикання, які під'єднують вхідний підсилювач до джерел зразкових напруг з однаковими значеннями +1 В і -1 В вихідних напруг. Імітація напруги зміщення операційних підсилювачів $\Delta \mathrm{U}_{1}, \Delta \mathrm{U}_{2}$ здійснюється включенням джерел напруг на входах ОП. Значення цих напруг вибрано типовим для сучасних мікросхем ОП \pm 10 мВ.

Імітується робота КПН змінним резистором, коефіцієнт передавання якого встановлюється програмним методом. При цьому коефіцієнт передавання визначається виразом:

$$
\mu=\frac{\mathrm{R}_{3}-\mathrm{R}_{\mathrm{H}}}{\mathrm{R}_{3}},
$$

де $\mathrm{R}_{3}$ - значення загального опору змінного резистора; $\mathrm{R}_{\mathrm{H}}$ - значення опору нижньої частини змінного резистора.

За відповідної підстановки отримаємо:

$$
\mu=1-\frac{N}{100},
$$

де $N$ - значення верхньої частини змінного резистора у відсотках.

Сигнал вихідного підсилювача під'єднується до входу фільтра за допомогою ключів, які змінюють його полярність відповідно до полярності напруги під'єднаного зразкового джерела. При цьому вхідні напруги фільтра залежно від полярності зразкової напруги визначаються виразами:

$$
\begin{gathered}
U_{B X 1}=\left(U_{0+}+\Delta U_{1}\right) \cdot \mu+\Delta U_{2}, \\
U_{B X 2}=-\left[\left(U_{0-}+\Delta U_{1}\right) \cdot \mu+\Delta U_{2}\right] .
\end{gathered}
$$

Відповідно похибки на вході активного фільтра знаходять за виразами:

$$
\begin{aligned}
& \Delta U_{B X 1}=\Delta U_{1} \cdot \mu+\Delta U_{2}, \\
& \Delta U_{B X 2}=-\left(\Delta U_{1} \cdot \mu+\Delta U_{2}\right) .
\end{aligned}
$$


Для усереднення вихідної напруги ВихП використано активний фільтр без постійного зміщення. Значення вихідної напруги від зміни коефіцієнта ділення змінного резистора вимірюється мілівольтметром.

Дослідження моделі проводилось в ручному і автоматичному режимах. В ручному режимі керування ключами здійснюється під'єднанням керуючих входів ключів до напруг живлення +12 В i -12 В відповідними резисторами з від'єднанням тактового генератора. В автоматичному режимі керування ключами здійснюється тактовим генератором, який формує прямокутні імпульси 3 амплітудою від -12 В до +12 В.

Результати дослідження моделі в ручному режимі при $\Delta \mathrm{U}_{1}=\Delta \mathrm{U}_{2}=10$ мВ подано в табл. 1.

Таблиия 1

Результати дослідження моделі калібратора напруги в ручному режимі

\begin{tabular}{|c|c|c|c|c|c|c|}
\hline$\mu$ & 0,01 & 0,2 & 0,4 & 0,6 & 0,8 & 1,0 \\
\hline $\mathrm{U}_{\text {вих }}, \mathrm{MB}$ & $-0,11$ & 212,01 & 414,01 & 616,01 & 818,01 & 1020,02 \\
\hline $\mathrm{U}_{\text {вих., }} \mathrm{MB}$ & 20,12 & 187,99 & 385,99 & 583,98 & 781,96 & 979,95 \\
\hline $\mathrm{U}_{\text {вихс }}, \mathrm{MB}$ & 10,005 & 200,000 & 400,000 & 599,995 & 799,985 & 999,985 \\
\hline$\Delta \mathrm{U}, \mathrm{mB}$ & 0,005 & 0 & 0 & 0,005 & 0,015 & 0,015 \\
\hline
\end{tabular}

3 аналізу значень, поданих в табл. 1, видно, що в ручному режимі керування ключами абсолютна похибка відтворень вихідного сигналу не перевищує 0,015 мВ і відповідно відносна похибка не перевищує 0,0015 \% для максимальних значень вихідної напруги калібратора.

На рис. 4 наведено графічні залежності похибок для різних значень напруги зміщення в ручному режимі за додатного і від'ємного значень зразкової напруги.

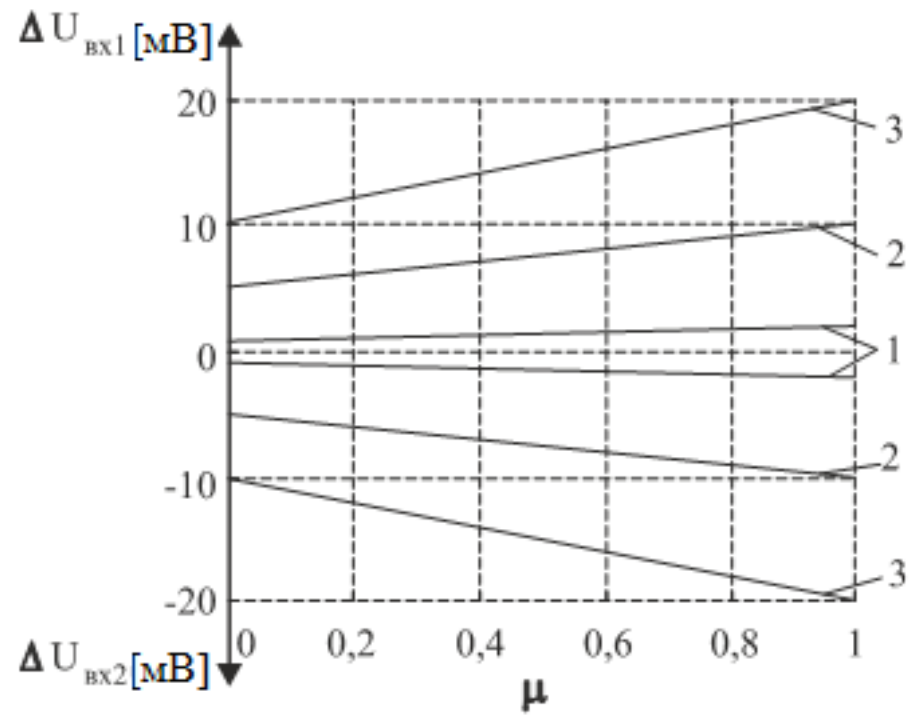

Рис. 4. Графічні залежності похибок вихідних сигналів у ручному режимі для різних значень напруг зміщення операційних підсилювачів:

$$
1-\Delta U_{1}=\Delta U_{2}=1 \mathrm{mB} ; 2-\Delta U_{1}=\Delta U_{2}=5 \mathrm{MB} ; 3-\Delta U_{1}=\Delta U_{2}=10_{\mathrm{MB}}
$$

3 аналізу графіка видно, що адитивні похибки симетричні для додатних і від’ємних значень зразкових напруг і відповідно повністю коригуються.

Результати дослідження моделі коригування похибок в автоматичному режимі залежно від різних частот ТГ при значенні напруг зміщення 10 мВ подано в табл. 2. 


\section{Результати дослідження моделі коригування похибок}

в автоматичному режимі $(\Delta \mathrm{U}, \mathrm{MB})$

\begin{tabular}{|c|c|c|c|c|c|c|}
\hline & $\mu, 01$ & 0,2 & 0,4 & 0,6 & 0,8 & 1,0 \\
\hline 50 & $-0,011$ & $-0,021$ & $-0,025$ & $-0,032$ & 0,034 & 0,041 \\
\hline 100 & $-0,037$ & $-0,310$ & $-0,420$ & $-0,810$ & $-1,052$ & $-1,150$ \\
\hline 250 & $-0,042$ & $-0,397$ & $-0,788$ & $-1,109$ & $-1,620$ & $-2,020$ \\
\hline 500 & $-0,045$ & $-0,440$ & $-0,845$ & $-1,197$ & $-1,822$ & $-2,446$ \\
\hline 750 & $-0,048$ & $-0,464$ & $-0,892$ & $-1,332$ & $-1,849$ & $-2,462$ \\
\hline 1000 & $-0,049$ & $-0,489$ & $-0,946$ & $-1,422$ & $-1,894$ & $-2,540$ \\
\hline
\end{tabular}

3 аналізу значень, поданих у табл. 2, видно, що під час збільшення частоти перемикання ключів абсолютна похибка калібратора зростає і на частоті 1000 Гц вже становить 2,54 мВ. Таке суттєве зростання похибок структури калібратора постійного струму, напевно, зумовлене особливостями побудови еквівалентних схем електронних компонентів у використаному програмному середовищі. 3 цією метою було промодельовано вплив напруг зміщення ОП $\left(\Delta \mathrm{U}_{1}=\Delta \mathrm{U}_{2}=10 \mathrm{MB}\right)$ на вихідну напругу калібратора напруги постійного струму на частоті 50 Гц для чотирьох різних випадків:

1) за відсутності напруг зміщення в структурі калібратора, вихідні напруги яких можна прийняти як опорні значення;

2) за наявності тільки джерела напруги зміщення $\Delta \mathrm{U}_{1}$ на вході вхідного підсилювача (вихідна напруга $\mathrm{U}_{1}$;

3) за наявності тільки джерела напруги зміщення $\Delta \mathrm{U}_{2}$ на вході вихідного підсилювача (вихідна напруга $\mathrm{U}_{2}$ );

4) за наявності обох джерел напруг зміщення $\Delta \mathrm{U}_{1} \mathrm{i} \Delta \mathrm{U}_{2}$ на входах обох підсилювачів (вихідна напруга $\mathrm{U}_{12}$ );.

Результати дослідження подано в табл. 3.

Таблиия 3

Результати дослідження впливу напруг зміщення на вихідну напругу калібратора напруги постійного струму

\begin{tabular}{|c|c|c|c|c|c|c|c|}
\hline \multirow{2}{*}{$\mu$} & \multirow{2}{*}{$\mathrm{U}_{0}, \mathrm{MB}$} & \multicolumn{2}{|c|}{$\mathrm{U}_{1}$} & \multicolumn{2}{|c|}{$\mathrm{U}_{2}$} & \multicolumn{2}{c|}{$\mathrm{U}_{12}$} \\
\cline { 3 - 8 } & & $\mathrm{U}_{\mathrm{B}}, \mathrm{MB}$ & $\Delta, \mathrm{м \kappa B}$ & $\mathrm{U}_{\mathrm{B}}, \mathrm{MB}$ & $\Delta, \mathrm{м \kappa}$ & $\mathrm{U}_{\mathrm{B}}, \mathrm{MB}$ & $\Delta$, мкB \\
\hline 0,01 & 9,9892 & 9,9898 & $-0,6$ & 9,9884 & 0,8 & 9,9885 & 0,7 \\
\hline 0,2 & 199,9795 & 199,9787 & 0,8 & 199,9801 & $-0,6$ & 199,9787 & 0,8 \\
\hline 0,4 & 399,9759 & 399,9752 & 0,7 & 399,9751 & 0,8 & 399,9753 & 0,6 \\
\hline 0,6 & 599,9683 & 599,9692 & $-0,9$ & 599,9691 & $-0,8$ & 599,9692 & $-0,9$ \\
\hline 0,8 & 799,9665 & 799,9672 & $-0,7$ & 799,9658 & 0,7 & 799,9673 & $-0,8$ \\
\hline 1 & 999,9598 & 999,9588 & 1,0 & 999,9589 & 0,9 & 999,9588 & 1,0 \\
\hline
\end{tabular}

Аналізуючи табл. 3, бачимо, що нескориговане значення абсолютної похибки досліджуваної структури калібратора не перевищує \pm 1 мкВ, що дає змогу зробити висновок, вплив напруг зміщення коригується до значень придатних для більшості практичних використань.

\section{Висновки}

Запропонований метод коригування адитивної складової похибки калібраторів напруги постійного струму на основі подвійного комутаційного інвертування теоретично дозволяє скоригувати їх адитивну складову похибку до значень, які не перевищують \pm 1 .мкВ. 
В автоматичному режимі моделювання значення похибок досліджуваної структури калібратора зростають із збільшенням частоти тактового генератора, який призначений для керування ключами. Це вимагає детальнішого теоретичного та експериментального дослідження причин збільшення мультиплікативної складової похибки розробленої структури калібратора напруги 3 автоматичним коригуванням похибок.

Результати досліджень можуть бути використані при побудові засобів першого ієрархічного рівня кіберфізичних систем.

1. Яиук В., Янович Р., Здеб В. Можливості оперативного калібрування промислових вимірювачів напруги // Вимірювальна техніка та метрологія. - 2013. - № 74. - C. 121-127. 2. V.O. Yatsuk, M.M. Mykyjchuk, Remote Errors Correction of Multi-Channel Cyber-Physical Measuring Systems. - "Advances of Cyber-Physical Systems" ("Досягнення у кібер-фізичних системах"), No. 1, Lviv Polytechnic Publishing House, 2016. - P. 16-21. 3. Mykola MYKYYCHUK, Yuriy YATSUK, Orest IVAKHIV, Roman MATVIIV. Voltage and Resistance Calibrators for Verification of Industrial Instrument Applications. - Proceedings of Metrology Commission of Katowice branch of Polish Academy of Sciences. Series: Conferences No. 21. - XII Conference "Problems and Progress in Metrology'2016", Szczyrk, 05-08 czerwca 2016 r. - P. 114-117. 4. Яиук Ю., Тимчук О. Коригування похибок діодних ичиррових термометрів // Вимірювальна техніка та метрологія, № 72. - 2011. - С. 50-54. 5. П. С. Свтух, T. М. Пелешок Властивості алгоритму корекиї систематичних похибок з використанням розрахункових поправок // Методи та прилади контролю якості. - 2006. - № 16. - С. 93-94. 6. Бойко О., Столярчук П., Яиук В., Матвї̈в В. Покращення метрологічних характеристик серійних переносних калібраторів опору, напруги, струму // Вимірювальна техніка та метрологія. - 2000. № 56. - С. 78-81. 7. Яиук Ю., Янович Р. Коригування адитивної складової похибки кодо-керованих калібраторів напруги // Тези допов. II Міжнар. наук.-практ. конф. "Управління якістю в освіті та промисловості: досвід, проблеми та перспективи”, 28-30 травня 2015 - Львів: Наи. ун-т “Львівська політехніка”, С. 228-229. 